\title{
Ciências da Comunicação
}

\section{Origens, mutações e horizontes epistemológicos do fenômeno glocal - dos interesses normativo-celebrantes do campo corporativo às ressignificações tensionais nas ciências humanas e sociais}

Epistemological origins, changes and horizons of the glocal phenomenon - from the normative-celebrative interests of the enterprise field to the tensional resignifications in the humanities and social sciences

\section{EUGÊNIO TRIVINHO}

Professor do Programa de Estudos Pós-Graduados em Comunicação e Semiótica da

Pontifícia Universidade Católica de São Paulo - PEPGCOS/PUC-SP

<eugeniotrivinho@uol.com.br>

\section{RESUMO}

Contribuindo para a renovação do debate sobre as relações entre o local e o global na cultura contemporânea, o texto mapeia e discute interpretações sobre o fenômeno glocal e seu processo derivativo, a glocalização, desde o seu aprisionamento terminológico-celebrante no campo corporativo até a sua inserção reflexivo-descritiva nas Ciências Humanas e Sociais, em especial a Comunicação, de que o texto é um indicador. A historicização inclui a crítica a dois pressupostos correntes: a da preponderância do local sobre o global (que deprecia a função social-histórica e político-econômica velada das tecnologias do tempo real, na base dos interesses pós-industriais que as sustentam) e a do absolutismo do global e da globalização (que, ao radicalizar a percepção das tendências correntes, relativiza a importância socioestrutural do local) - críticas sinalizadoras do tratamento teórico-epistemológico tensional proposto pelo autor em relação ao tema, sob a inspiração das tendências de hibridização contemporânea.

Palavras-chave: Civilização mediática; Fenômeno glocal; Tecnologias e redes de comunicação em tempo real. 


\section{ABSTRACT}

Contributing to renew the debate on the relations between local and global in the contemporary culture, the article maps and discuss some interpretations of the glocal phenomenon and its largest process, the glocalization, since its terminologicalcelebrative imprisonment in the enterprise field to its theoretical-descriptive insertion in the humanities and social sciences, especially in the communication area, about which the text can be considered an example. This historicization includes the critique to two common assumptions: the preponderance of the local on the global (that belittles the social-historical and political-economic role of the technologies and networks in real time, included all post-industrial interests that support them) and the absolutism of global and globalization (which, when it radicalizes the perception of the present trends, relativizes the socioestructural importance of the local - critiques along which the author signalizes his tensional theoretical-epistemological approach about the theme.

Keywords: Mediatic civilization; Glocal phenomenon; Technologies and networks of communication in real time.

\section{A água é uma chama molhada."}

(NOVALIS, 1992, p. 111; grifos do autor)

\section{O celeiro corporativo do glocal}

Onsenso internacional existente indica que a conjuminação entre global e local num único significante - glocal, esta palavra hoje crucial para o ulterior entendimento do modus operandi fundamental da civilização mediática - foi originalmente constituída no mundo corporativo japonês, na década de 1980. A apócope criativa visava responder, nesse celeiro, a uma situação histórica cada vez mais globalizada e interdependente política, econômica e culturalmente e com repercussões continuadas no domínio dos negócios, na qual uma empresa vê-se compelida a fazer uso de seu capital disponível de flexibilidade adaptativa a culturas locais, em sinal de respeito às características socioculturais das comunidades dentro das quais se instala e atua, a fim de cumular feitos públicos à imagem institucional matricial da empresa, às suas reservas ético- 
estratégicas de responsabilidade social e, obviamente, aos seus interesses de expansão do valor de troca.

Nesse domínio, as iniciativas decisórias e os processos operacionais correspondem invariavelmente ao significado mais banal desse termo glocal: uma matriz multinacional determina princípios para a atuação de suas filiais em território alheio, em diferentes continentes. Em releitura complementar e alternativa, num planeta espacialmente apocopado pela realidade intermediática em tempo real, é necessário vincular a inexorabilidade da ação prático-corporativa no contexto regional a diretrizes matriciais de ação traçadas a partir de uma análise de conjunto, criteriosa e estratégica, sobre as vicissitudes e possibilidades do contexto político-econômico mundial. A axiomática desse procedimento transfronteira não deixa dúvidas: trata-se da subordinação econômica e financeira do local ao global sob o álibi eufêmico da adaptabilidade cultural-corporativa do global ao local. Assim se deve entender a elocução propositiva "é preciso glocalizar"1. Tal esquema executivo-operacional de política corporativa traduziu-se (e fixou-se com êxito) num mote vicioso, comum e espraiado: pensamento global, ação local. Fica, não por acaso, evidente - curiosamente sem escamoteação ou subterfúgios - que a propensão valorativa nesse terreno é, majoritariamente, única, típica da perspectiva empresarial, em nome da estabilidade necessária dos negócios: deve ser evitado tudo o que escapa à fleuma normativo-celebrante e à afirmação positivista do que é, em prol de novos horizontes egressos do emergente - próspero, embora perigoso - terreno de atuação.

\section{Difusão terminológica e multissetorial do glocal: incorporação e trajetória semântica do termo nas Ciências Humanas e Sociais}

Derivações dessa perspectiva sobre o glocal na esfera corporativa viram-se reproduzidas em campos de atuação e saber os mais diversos, como a ecologia, a 
geopolítica, a educação, a religião, o esporte, e assim por diante, não raro com sinal valorativo invertido, de contradito às condições de glocalização empresarial vigentes, em nome de um outro modelo de mundo interdependente, mais justo e solidário.

Desde a década de 1980, o termo glocal acabou por se tornar, então, nome de site, de evento científico, de associação de pessoas, de revista acadêmica, de igreja evangélica, de grupo empresarial etc ${ }^{2}$.

Nas Ciências Humanas e Sociais, o termo adquiriu acepção mais abstrata, alçada ao patamar de categoria epistemológica, portanto, com franjas de significação transformadas, mais complexas e extensas, evidentemente menos pragmáticas, funcionalistas e comprometidas com os imperativos do valor de troca.

Nesse âmbito, o primeiro a laborar o conceito foi Roland Robertson. Nos principais escritos do sociólogo britânico sobre o assunto (1992, 1994, 1995, 2001, 2002, 2003), o termo comparece no contexto de preocupações teóricas com a formação social e política de novos modos de subjetividade, com os processos de construção da consciência e/ou de conscientização individual e coletiva sobre os problemas, desafios e horizontes do mundo globalizado e com as condições atuais da ação social correspondente e orientada à transformação. Nessa direção, patenteia-se o interesse de não apenas incorporar o uso do conceito de glocalização no debate sociológico sobre a globalização (tanto na economia, quanto na cultura), mas também de defender enfaticamente a substituição desta última pelo mencionado conceito, na raiz do glocal. Com essa carga de significação, é inconcebível não assinalar que, para Robertson, o processo de glocalização, por seu potencial de repercussões variadas na vida prática, deve ser apreendido e assumido no colo de um conceito fortemente propositivo, de engajamento planejado entre sujeito e objeto, mesmo sob todos os riscos de uma sinergia teoricamente perigosa entre reflexão (que se requer autônoma a priori) e empiria processual abordada, entre subjetividade e recorte de foco, entre 
noção complexa (no caso, autopromovida) e substrato do mundo ("colado" a ela). Ao subordinar a utilização (mais descritiva que tensional) da nova terminologia à evidência inquestionável do sujeito social e às formas de percepção sobre o seu papel em relação à alteridade e às tendências do existente, Robertson assegurou a validação do conceito no plano maleável da construção cultural das relações sociais, corroborando - sem outra alternativa, na verdade - a perspectiva sociológica moderna ou modernista, centrada nas possibilidades de mudança das estruturas atuais de vida (em conjunto ou em domínios setoriais) com epicentro numa cidadania socialmente comprometida e consequente.

Nesse âmbito de consideração qualificada, comparecem, com efeito, importantes procedimentos metodológicos, como o tratamento sistemático e formal dos conceitos de glocal e de glocalização dentro do perímetro do trabalho científico; e como o reposicionamento, no centro da teoria social e cultural, da questão da interpenetração entre universal e particular, fatores que constituem o emblema distintivo do processo de glocalização. Igualmente, comparecem abordagens temáticas nucleares, como a relação renovada entre homogeneização e heterogeneização no plano da cultura, pelo que também se reatualiza a ênfase no imperialismo cultural; a imaginação de identidades singulares, dentro das quais se destacam - conforme antes mencionado - a questão da consciência de mundo e as perspectivas de atuação nele; a transição entre modernidade e pós-modernidade e, dentro dela ou a ela ligadas, as relações entre conflitos culturais e processos socioeconômicos e as mudanças nas categorias de tempo e espaço; e, especialmente, o mundo glocal e seus desafios, a relação entre ele e o desenvolvimento de meios/processos de comunicação (embora ainda em patamar epistemológico insuficientemente sintonizado com o estado da arte da organização tecnológica da cultura contemporânea, a saber, sem a desejada costura temática estrita, exclusiva e continuada com os media (de massa, interativos ou híbridos), de maneira a 
considerá-los fundacionais, com caráter sine qua non, para a vigência do mundo glocal tal qual é e tem sido, bem como para a existência humana e para a sua expressão sociotecnológica nele); ${ }^{3}$ a relação entre glocal e eventos internacionais de monta, como o ataque terrorista às torres gêmeas nos Estados Unidos ou os movimentos internacionalizados de contestação à globalização instituída e à invasão do Iraque e do Afeganistão; entre outras temáticas relevantes.

Esses procedimentos metodológicos e focos temáticos se operam mediante utilização expressa e majoritária do termo glocalização por remissão recorrente aos seus dois processos constituintes, globalização e localização, o que não deixa de patentear, primeiro, a aceitação da empiria processual supostamente disjungida de ambos os termos (por assim dizer, acolhidos como tais, linguística e semanticamente "em separado"), mesmo quando explicitados numa mesma questão - local/global -; e, segundo, nesta ordem, a pressuposição (em tudo discutível, se real) de que a negociação interconceitual, na tessitura teórica - a três: globalização, localização e glocalização -, necessita ser constituída sob a preexistência desse alijamento fatorial.

Não obstante, evidenciam-se, no labor de Robertson sobre a problemática da glocalização, dois pontos frutíferos. Do ponto de vista epistemológico, seus escritos priorizam a preocupação fundamental com a dinâmica da hibridação e com a apreensão conceitual mais adequada, já no plano significante, da natureza de seu produto histórico, o híbrido, relativizando, pois, o risco - sempre presente - de se operar, no pensamento e na linguagem, voluntária ou involuntariamente, categorias dicotômicas ou bipolares (global e local, público e privado, próximo e distante, coletivo e individual, externo e interno etc.). Do ponto de vista fenomênico, justamente como repercussão do assinalado, Robertson demonstra, igualmente, preocupação com a emergência socialhistórica de fenômenos híbridos, do que se subentende, à luz do presente texto, tratar os seus escritos, direta ou indiretamente, da emergência de fatores socioculturais e 
político-econômicos que radicam no desenvolvimento e na reprodução da civilização mediática em tempo real.

Esses apontamentos, malgrado sucintos, deixam claro que, em sua compreensão dos arranjamentos sociais das últimas décadas, Robertson apreendeu, de toda a composição fenomênica pouco clara e ligada ao glocal pelo crivo da cultura e das práticas sociais, o essencial mais complexo subsumido no sincretismo sociotécnico dessa categoria, na mesma medida em que - deve-se enfatizá-lo - deixou-o escapar, paradoxalmente, em outra qualidade, conexa, a de ponto de partida teórico sine qua non e eixo de multiestruturação epistemológica sobre a especificidade e dinâmica da civilização tecnológica em curso, gestada exclusivamente desde as primeiras décadas do século XX, a partir do advento e sofisticação progressiva das tecnologias do tempo real. $\mathrm{O}$ fato de Robertson não ter reconhecido integralmente um potencial tecnocultural maior e latente e a amplitude histórica da matéria-prima em retrabalho, no que tange à sua constituição como prisma conceitual de visão sobre as características basilares da cultura contemporânea e sobre a tipicidade do processo civilizatório em curso, fincados no vetor mediático, para, a partir daí, em retorno semântico organizado sobre a matéria-prima, operar-se o reescalonamento da categoria à sua devida macroescala social-histórica, em vínculo com a arquitetura do tempo real, na forma-fluxo de toda uma civilização mediática afluente, deve-se com certeza mais ao seu pertencimento intelectual a uma tradição sociológica internacional que, majoritária e seguidamente, relativiza o estatuto e o papel centrais - na mencionada escala - da comunicação e de seus modos de apropriação (de aparatos, de produtos, de conteúdos etc.) na estruturação dinâmica recorrente do modus vivendi contemporâneo. Seja como for, radica no bojo dessa filiação metodológica (vis-à-vis, sempre da ordem de adesões relativamente inquestionadas, voluntárias ou involuntárias) uma restrição percepcional e teórica na qual se decide, no plano dos pressupostos referendados, a lacuna de 
reconhecimento apontada a respeito da dimensão fundante dos media em relação à (des)organização do social, da política e da economia, bem como (a respeito) do princípio de que, dado o caleidoscópio de facetas grandemente desconhecido em que essa dimensão se converteu, constitui, no mínimo, desperdício cognitivo (na direção, no limite, de um desserviço para a história do pensamento) não extrair diretamente dela, para a compreensão do mundo contemporâneo, uma epistemologia renovada, com epicentro na categoria do glocal e articulada no plano explícito da tessitura argumentativa; ou, numa metáfora, não erigir, a partir dessa dimensão (para além de qualquer trabalho relevante ao nível exclusivo da semântica), um edifício terminológico correspondente, especial e tensional, fincado no processo de glocalização (entendido como) vinculado à mediatização planetária por dispositivos comunicacionais.

O presente texto, acolhendo razões distintas a esse procedimento, procurou, modestamente, compensá-lo, no que por ora foi possível, no interesse fundamental da crítica teórica socialmente orientada. A razão para isso, no que diz especificamente respeito à configuração contemporânea do social-histórico, expressa como civilização mediática, é relativamente simples, mas merece notação assertiva: o fenômeno glocal, doravante mundializado, existe, única e exclusivamente, porque vigoram, proliferados no social, dispositivos, meios e redes de comunicação, substratos voláteis de todas as formas de apropriação e interação mediada com a alteridade e com o mundo e que radicam, portanto, na base da condição glocal do social-histórico e do modus vivendi cotidiano, seja na esfera do trabalho, seja na do tempo livre e de lazer. Não houvesse esses fatores comunicacionais, o mencionado fenômeno, de que se fala hoje em vários campos de interesse intelectivo e/ou prático, simplesmente não existiria e, com isso, restaria também prejudicada a certeza (mínima, inclusive) acerca do fundamento empírico da evidenciação (de que, desde meados do século $X X$, vive-se num perpétuo trânsito de fases) da civilização mediática. 
Esse apontamento repõe, por novo ângulo, a intenção precípua do presente texto: é necessário conduzir a discussão sobre a questão e o respectivo conjunto internacional de preocupações reflexivas e temáticas para dentro estritamente (do horizonte teórico acerca) dessa formação social em tempo real e de suas reconfigurações tecnoculturais e transpolíticas. Esse deslocamento - diminuto mas, de monta por similaridade ao de placas tectônicas em relação a superfícies estabelecidas - assinala, senão uma reorientação stricto sensu dos rumos da teorização a respeito, uma contribuição definida na direção dessa proposição, a da reorientação estrutural do debate a partir do deslocamento de seu locus de partida e de sequência. Eis por que a argumentação, que a rigor necessita ser sempre remodulada de acordo com a natureza e escala do objeto, teve de sofrer mudanças significativas de foco e de trajetória, o que só poderia se expressar evidentemente numa tessitura epistemológica peculiar e distinta da maioria das congêneres sobre o tema.

Ao que foi possível certificar-se até a publicação deste artigo, no campo de estudos interdisciplinares sobre comunicação, organização do social e cibercultura (ou nomenclaturas similares, como sociedade da informação, do conhecimento ou de redes), no contexto seja brasileiro, seja internacional, rareiam investigações nesse caminho de compreensão. A maioria dos estudos sobre o fenômeno glocal passa ao largo da tarefa fundamental (e de tal forma oportuna, pela urgência) de esculturação de uma epistemologia renovada a partir da evidência acima, a da precessão ou ascendência condicional dos media e de suas respectivas formas de apropriação social. Em geral, as abordagens se inserem no arco do que aqui se considera o glocal lato sensu, a saber, a mescla profusa entre local e global no plano simbólico e imaginário da cultura sem a intermediação necessária e direta de tecnologias e redes em tempo real. Essas abordagens não costumam "descer" ao pomo da civilização glocal, tarefa iniciada com a nomeação do fenômeno glocal propriamente dito, isto é, o glocal stricto sensu, 
aquele exclusiva e fortemente inserido no social-histórico pela vigência das tecnologias do tempo real e, portanto, umbilicalmente vinculado ao contexto glocal de acesso/ recepção/retransmissão/irradiação comunicativa e à condição glocal da história e da existência contemporânea, multiconceituação essencial - quer-se crer - para a compreensão mais apurada das condições materiais, simbólicas e imaginárias da experiência humana na fase atual do capitalismo tardio, informacional e financeirizado. É provável (e bastante razoável reconhecê-lo) que essa perspectiva epistemológica somente a área de Comunicação - como campo intelectual renovado e emergente na divisão social internacional do conhecimento - poderia prover, como contribuição ao entendimento da organização infotecnológica do social contemporâneo.

A esse respeito, talvez tenha sido Paul Virilio (1995) quem preliminar e paradoxalmente - ele que era arquiteto, urbanista e autodidata em assuntos militares mais bem sinalizou, para a teoria, a sociologia e a filosofia da comunicação, a dimensão preocupante da condição glocal, no interesse de uma ensaística tensional, ao mencionar o termo glocal num contexto de discussão sobre o significado periclitante da velocidade tecnológica (do tempo real) trazido pelo cyberspace - consequências da ordem de um eventual acidente generalizado, por irradiação informacional iminente, provocado por dolo ou ao acaso, no arco sempre sombrio de uma militarização socialmente velada, de que grande parte da obra do pensador francês é a memória sistemática mais fecunda e esclarecedora (Virilio, 1999).

Outros autores do campo das Ciências Humanas e Sociais selaram trajetória importante de remissão mais recorrente ao termo glocal, já tomado em arranjamento mais próximo a elemento de epistème social, cultural e/ou politicamente orientado, contribuindo para o desdobramento de sua rica mutação semântica.

Tributário das contribuições teóricas e temáticas de Robertson, Massimo Canevacci (1996) apreendeu a problemática envolvida na empiria processual abrangida por 
essa categoria, abordando formas de sincretismo no âmbito das relações sociais e culturais especialmente das metrópoles, o que, no presente artigo, corresponde ao amplo cenário social-histórico constituído e marcado pelo processo de glocalização lato sensu, conforme mencionado acima.

Em ensaio dedicado à reflexão sobre a renovação do papel e do lugar da política na sociedade da comunicação, Albino Rubim (2001) mapeia as consequências teóricas e práticas do reconhecimento da realidade social e cultural glocal e os horizontes a serem necessariamente explorados pelas práticas políticas e telepolíticas de esquerda em nome de avanços democráticos na esfera dos media e do Estado, bem como em toda a sociedade. Embora não conceda aos conceitos de glocal e de glocalização tratamento epistemológico estrito - não era esse o seu propósito -, Rubim chama especial atenção para a urgência histórica de atualização concreta dessa política de transformação social, em contribuição à superação de sua inevitável defasagem - do ponto de vista de seu modus operandi e de sua eficácia pública, menos do de seus princípios de base -, num cenário sociotecnológico em rede inteiramente diverso do de fases pregressas do capitalismo.

Na Itália, merece especial menção, pela importante contribuição à reflexão sobre a matéria, a coletânea organizada por Franciscu Sedda (2004). Estudiosos e interessados na questão do glocal poderão encontrar nessa rica obra artigos de envergadura e excelente qualidade, de autores preocupados em demonstrar, em conjunto, quão complexas se constituem realmente as temáticas relativas ao assunto, a ponto de serem passíveis de tratamento multidisciplinar em áreas tão diferentes e solidárias como a comunicação, a semiótica, a filosofia, a sociologia, a política, a história e a arquitetura, entre outras. Abrigando desde reflexões teóricas genéricas a análises de casos e experiências específicos, a coletânea inclui questionamentos acerca da validade da utilização do neologismo de referência até a afirmação dos pressupostos 
semióticos envolvidos na empiria processual correspondente; e, nesse caminho, alcança sensivelmente a dimensão imaginária do glocal, tal como ele se apresenta como nova utopia ${ }^{4}$.

Sob esse espectro de fundo, a agenda temática da obra abarca estudos sobre as interações sociais, as condições do urbano (com ênfase nas metrópoles), as paisagens sonoras, a expressão em arquitetura, o jornalismo televisivo e, mais amplamente, a produção, difusão e consumo de produtos culturais e mediáticos (informações, imagens, música etc.); o discurso do imperialismo cultural, a opinião pública mundial, os novos atores sociais e políticos (doravante glocais) e o confronto com o modelo vigente de globalização, as práticas de guerra e assim por diante - temas abrigados em argumentações a maioria sem remissão direta e continuada aos media ou à realidade mediática (em plano explícito ou de fundo); e, no caso positivo (dessa previsão), ainda assim, sem a extração estrita da epistemologia que lateja nessa relação ou sem traduzir dela as consequências teóricas para a construção sistemática de uma epistemologia orientada à compreensão da estrutura dinâmica da civilização mediática avançada.

Com esta composição múltipla, a coletânea apura as consequências para o sujeito e para o ser, para a experiência do espaço e do tempo e para a vida cotidiana, para as ações políticas de protesto e para a afirmação de direitos, para a cidade e comunidade, para a construção da subjetividade, da identidade e da representação de mundo etc. No todo, o projeto nuclear da obra pressupõe, significativamente, o reconhecimento da realidade glocal atual como "potencial raiz e horizonte do mundo" (Sedda, 2004, p. 10).

\section{Crítica a pressupostos correntes}

\section{a) Preponderância do local em relação ao global}

No cômputo geral da miríade de argumentações surgida nas últimas décadas sobre a tensa relação de poder entre os processos transnacionais da economia, da política 
e da cultura e as experiências vividas no contexto concreto das cidades - reflexões que evidentemente envolvem, embora implicitamente, a fenomenologia extensiva do glocal -, tornou-se comum a tese ou o pressuposto do predomínio da realidade local/ regional sobre o (ou em relação ao) global (o que pertence a alhures e se mantém fiel a ele) ou o que o representa (pessoas, experiências, temas, discursos, imagens etc.); e (igualmente predomina) a necessidade de reação a essa situação, de responder ao global, desafiando-o, em resistência à ameaça por ele representada à identidade regionalmente construída.

Admirável esforço teórico de qualificação propositiva desse caminho de argumentação, no Brasil, foi o demonstrado por Augusto de Franco (2003/2004). Para ele, a glocalização dimana de imagens e ideias vinculadas à planetarização dos problemas, desafios e horizontes da vida humana, bem como à consciência social e individual dessa planetarização (Franco, 2003/2004, pp. 109-122).

$\mathrm{O}$ autor traça sucintamente a história do glocal através do que designa de ideiasforça dessa planetarização, ideias-avatares de um mundo totalizado, em prol do comunitarismo, aquele egresso de uma "revolução comunitária", que o autor prefere traduzir, em seu estudo, como "revolução do local” (Franco, 2003/2004, p. 118). A lógica da conjugação, interna à natureza do paradoxo, caracteriza essa condição holográfica mundializada: "planeta-e-comunidade é a realidade glocal" (Franco, 2003/2004, p. 118). Tal justaposição intrafenomenológica de escalas se denega, com efeito, em seus fundamentos, na medida em que, para além de qualquer relação horizontal e distendida, incuba (a possibilidade de) uma flexão de monta: a emergência de um horizonte de inversão total de fatores que propende para a afirmação do local sobre o global ou, em outras palavras, para a tendencial submissão ajustadora deste último àquele. Arrazoado analítico tonicamente valorativo, em releitura política e politizante de seu objeto, a tese da "revolução do local" põe-se, em injunção argumentativa 
subsequente, atrelada à promessa utópica de um mundo melhor - uma Terra-Frátria -, mais humanitária, solidária e pacífica, assim como democrática, sustentável e ligada à comunidade (Franco, 2003; 2004, pp. 118-120).

Nesses dois passos - preponderância do local e esperança emancipatória -, reside tanto à força propositiva da obra quanto a lacuna principal de seu esquema teóricoexplicativo. Bem argumentada, conclui, com efeito, equivocadamente, no que tange ao primeiro aspecto. (A propensão à aposta teórico-prática no devir constitui - reconheça-se - matéria de crença e, para todos os efeitos, prevalecerá aqui intocada.) $\mathrm{Na}$ condição glocal da história e da vida cotidiana, em sua significação mediática hoje articuladora do processo civilizatório, conforme aqui laborada, já não vigora polo que se sobreponha a seu antípoda ou diverso.

A relação de tensão que, há algumas décadas, preexistia entre todos os elementos binários ou pares opostos transitou para uma unidade de síntese derradeira, estagiando, sem umbral adiante, numa co-fusão aparentemente intransitiva, sem dialética progressiva e transcendente, exceto se para dentro de si mesma, como amálgama inquieto e continuado, em razão do aspecto tensional imanente, jamais perdido. Imaginário e real, público e privado, coletivo e individual, próximo e distante, interior e exterior, masculino e feminino, familiar e estranho, e assim por diante, em encadeamento de dualidades estendidas - após mais de seis décadas de processo civilizatório glocalizado (para somar apenas o transcurso posterior à Segunda Guerra Mundial) - nenhuma dessas figurações maniqueístas se reconhecem como fenomenologicamente distintas uma das outras; encontram-se, na empiria social, embrenhadas de tal forma que somente uma pesquisa estrita, versada em filigranas e sob preocupações exclusivamente analíticas, poderia determinar, se ainda possível, as respectivas silhuetas e fronteiras, bem como os aspectos conflituosos internos. 
Repõe-se aqui a figura inconfundível e dinâmica do híbrido, na qualidade de dialética estagiária em momento específico da gramática de sínteses, ao modo seja de objeto, seja de processo - uma mescla inextricável entre um e outro num movimento integralizado e final, válida tão-somente nos estritos limites desse objeto e desse processo; numa apreensão mais apurada, uma hibridação que vigora como metavertente de grandeza autonomizada e unitariamente realizada, extática em sua circunvolução não-superativa, para além da mera contabilidade aditiva dos ingredientes que a constituem.

Não obstante, justamente em razão do estado permanente de equilíbrio precário aí compreendido (entre os elementos amalgamados e dissolutos), não resolvidos senão a cada dia, a mencionada relação de tensão, órfã da dialética, não se faz sem conformação de dominâncias estruturais ou conjunturais.

No caso da condição glocal, se, para prevê-lo em panorama, há alguma fatoração estrutural dominante, refere-se à subordinação de todos os contextos locais (conforme herdados do estirão milenar e ordinário da história pré-eletrônica) à rede global em que se converteu o tecido simbólico e imaginário das relações sociais em e entre zonas dromocratizadas e privilegiadas de todos os países (Trivinho, 2007) - subordinação sinérgica, irrecorrível e, ao mesmo tempo, sutilizada (sem tutelagem explícita) de uma dimensão a outra, no que diz respeito tanto à agenda sígnico-mediática nacional/transnacional, quanto à infraestrutura e ao conjunto de padrões tecnológico-operacionais de base para a circulação fluente dessa agenda. Prevêem-se, evidentemente, nesse intercondicionamento, o engendramento de tendências de tratamento informacional global-seletivo dos fatos locais ou regionais, as quais respondem, sempre pretensamente, pela perpetuação das condições glocais do processo civilizatório. Nesse pormenor, o glocal, tomado em sua manifestação fenomênico-mediática predominante, não perde, mesmo depois de décadas e apesar de seus deslocamentos de 
território cognitivo e transformações semânticas, a propensão de seu manancial corporativo de origem.

Esse é o aspecto historicamente distintivo da civilização tecnológica atual: além da originalidade do glocal como invenção tecnocultural (Trivinho, 2007), a fantasmagoria imagético-noticiosa que representa o todo-alhures se infiltrou no aqui e ali vicários - onde os corpos dos viventes se situam (e jamais deixarão de fazê-lo), de par com suas consciências individuais -, operando um efeito irremediável de reconstrução contextual dos respectivos campos próprios para, em ato simultâneo e em dimensão alargada, recompor-se diuturnamente ela mesma, imagèrie-informacional. Trata-se de uma subordinação sutil, remissiva, inelidível, a partir da qual os contextos locais precisam necessariamente lidar, em algum sentido ou intensidade, com os ventos frequentemente irradiados da cultura comercial circulante e satelitizada, representativa da dimensão global da vida social.

Em condições multicapitalistas, sob a inflexão de interesses estatais conjugados, senão sobredeterminadores, toda e qualquer adaptação do global ao local é puramente estratégica e dissimulada: faz-se tão-somente para cooptá-lo operacionalmente em favor de uma preponderância inconfundível e silenciosa. Essa interpenetração já inclui o ethos plurifacetado de apropriações sociais de tecnologias e redes; vive, na realidade, dele, depende dele, para, enredando cada vez mais o local e seus pertences, concretizar-se de modo ampliado, paradoxalmente no e a partir de seu entremeio.

Tal admissão, por mais problemática e difícil que politicamente seja, valida, para necessária ênfase, uma notação desdobrada: para além da mera crítica do comportamento tecnoculturalmente conservador de massas consumidoras e interativas, a asserção chama a especial atenção sobre o quanto vigora há décadas uma realidade operacional perversa, às expensas de todas as consciências, desejos e atuações (individuais e coletivas) em contrário: apropriações multilaterais - tanto 
mais as antropofágicas, em defesa ativa ou pressuposta da hegemonia das condições locais ou regionais - de tudo o que prefigura a globalidade não constituem senão justa e paradoxalmente o processo pelo qual o global, o que vem de alhures, se realiza, alastrando-se e enraizando-se, na escala do próximo, no terreno mais íntimo.

$O$ viés subordinativo aí compreendido patenteia-se na "placidez natural" com que o processo ocorre: a pressão permanente dimanada da própria existência fenomenológica e vocação irradiadora do global determina que as práticas de apropriação locais ou regionais dele jamais descansem, jamais deixem de se prever continuamente como emergenciais e necessárias. Elas precisam se fazer - e tão-somente assim serão práticas de apropriação - nas condições de base previstas pelo imperativo de uma pauta operacional primeira, aparentemente inescapável (ao menos até o momento e segundo os indicadores correntes). Quem ou o que, em contexto de luta por ascendência (político-tecnológica, sociocultural, econômico-financeira etc.) sobre espaços de influência, granjeou prerrogativa para conclamar e/ou seduzir para a vida acaba irremediavelmente por conceder as cartas, por mais que a autoria do processo, integralmente impessoal, reste sempre obliterada.

A façanha autopoiética e socialmente descentrada dessa operação de cooptação enredadora e dissuasiva do local pelo global radica no fato de tudo se processar sem elisão (da consciência) da soberania local e na "certeza" de esse reduto ainda estar supostamente no comando, quando todas as evidências acenam para o contrário (ou, se não, ao menos para situação matizada).

Simultaneamente a essa releitura da relação subordinativa de poder, feita sob o prisma do tempo real, regrado e desenvolvido por interesses transnacionais do capital e de Estados nacionais coalinhados a eles, convém enfatizar - em retomada ao já apontado - que o processo de glocalização é, antes, o resultado progressivo (embora não-linear e não-evolucionista) de um movimento histórico-tecnológico 
irreversível, que precisa ser apreendido, antes de tudo, por sua força fundante, a comunicação em rede, na base de suas tecnologias e modos sociais de apropriação, sem o que "as imagens e idéias planetarizantes" de que fala Franco (2003/2004). jamais poderiam traduzir sequer um suspiro demonstrativo de autoexistência. Por evidente, Franco leva acertadamente em consideração a importância das tecnologias e técnicas de comunicação, sem, contudo, atribuir-lhes o peso central ou nuclear que deveriam ter na explanação teórica sobre uma realidade que se nutre essencialmente da vivificação social multilateral desses recursos tecnocientíficos (objetalizados e procedimentais) disponíveis na vida cotidiana, da esfera do trabalho à do tempo livre e de lazer - um modus vivendi banalizado que, além do mais, sustém com, sem ou contra a voluntariedade dos viventes, a reprodução social-histórica do tardo capitalismo em rede.

\section{b) Absolutismo do global e da globalização}

Em caminho inverso, avaliação idêntica pode ser prevista acerca da supervalorização analítica e (quase) exclusiva do polo complementar/"oposto" - o global -, sobre o qual a literatura ensaística internacional é igualmente profusa desde o início da década de 1990. A obra - que se pode eleger, com justiça e reconhecimento, pelo esforço descomunal de sistematização e atualização de informações - como emblemática a respeito é a de Manuel Castells (2003). A argumentação do autor compreende - com exemplar clareza reflexivo-descritiva e fundamentação empírico-estatística, longe do economicismo fundamentalista vigente - como estando na base sine qua non da cultura global justamente as tecnologias e redes digitais; em palavras escalonadas, a empiria do fenômeno glocal e da glocalização das relações sociais.

Com efeito, na visão de Castells, tudo - absolutamente tudo - vigora como se apenas ou predominantemente global (isto é, sem relação sociotecnológica estrita com 
os lugares (sobretudo urbanos, já amplamente desterritorializados pelo tempo real): a economia, como de resto os mercados (de bens e de capital); as cidades; a ciência e a tecnologia, e assim por diante (mas não ainda a mão de obra, segundo dados da última década do século passado).

A esse respeito, recobra a atenção o tópico intitulado "Globalização versus regionalização" (Castells, 2003, pp. 152-157), dedicado a reexame negador e detalhado da tese da regionalização progressiva da economia global, egressa do início da década de 1990. A previsão estratégico-nomológica da preposição adversativa (versus) não deixa de ser sintomática, para além da mera precisão do relato sobre as argumentações econômicas vigentes à época. $\mathrm{O}$ termo mediador provê, no embate das teses, proeminência evidente (e exclusiva) para a globalização, em detrimento da segunda tendência.

Mesmo a reflexão sobre a relação entre "espaços de fluxos" e "espaços de lugares" (Castells, 2003, pp. 466-521), na qual a argila social-histórica típica da glocalização se colocaria em toda a sua propriedade fenomenológica e problemática sociocultural e político-econômica - reflexão embasada em testemunho de campo no bairro de Belleville e na cidade de Tóquio -, deixa de levar em conta a hibridação mais intensa, funda e corrente entre ambas as dimensões a partir dos usos sociais de tecnologias e redes em tempo real, no mundo do trabalho e no tempo livre, notação cuja plenitude simbólica e esclarecedora somente (mas não exclusivamente) uma categoria como a do glocal permitiria atingir.

O argumento da sobredeterminação do global/espaço de fluxos em relação ao local/ espaço de lugares, exposto não sem relativo e justificado alarmismo (Castells, 2003, pp. 517-518), permanece, em essência, correto, em contraposição à argumentação dos autores anteriormente comentados. Não obstante, a reflexão de Castells se desdobra com esteio na separação analítica - melhor ainda, na polarização (de monemas e respectiva semântica) - das categorias trabalhadas (lugar/localização/localidade; 
global/globalização). A costura necessária se cumpre mediante reconhecimento de uma oposição dialética (vale dizer, uma relação conflitualmente complementar) entre as partes teoreticamente previstas, a qual é igualmente abrigada, do ponto de vista teórico-estratégico, como forma de privilegiar a tensão, em vez da harmonia, na estrutura dinâmica das relações sociais, em escala nacional e internacional.

Em síntese, a obra de Castells, grandemente dedicada aos novos arranjamentos econômico-financeiros na civilização mediática em tempo real, poderia ser certamente reescalonada - com autossuperação do binarismo metafísico ocidental, hoje totalmente descompassado, no plano do significante como do significado, para a apreensão dos fenômenos híbridos -, se reconhecesse, no extenso feixe de elementos fatuais laborados, a empiria material e processual do fenômeno glocal.

\section{Conclusão}

Sejam quais forem as interpretações que se lhes dê, as tendências sociotecnológicas correntes, fortemente fustigadas por cartadas progressivas de inovação tecnológica a cada temporada, ao calor da competição industrial e pós-industrial em escala internacional, por parte das empresas do ramo, indiciam que o processo social-histórico da glocalização, nos termos aqui especificados, apenas inaugurou a sua epopeia, sem anúncio do respectivo porto histórico de destino, nem antecipação de sinais confiáveis acerca da época de sua entropia, valendo-se da adesão tácita dos viventes para elidir qualquer consulta prévia sobre a legitimidade de sua autopoiesis.

\section{REFERÊNCIAS}

BOURDIN, Alain. La question locale. Paris: Presses Universitaires de France, 2000.

CANEVACCI, Massimo. Sincretismos: uma exploração das hibridações culturais. São Paulo: Studio Nobel; Istituto Italiano di Cultura; Instituto Cultural Italo-Brasileiro, 1996. 
FRANCO, Augusto de. A revolução do local: globalização, glocalização, localização. Brasília; São Paulo: Agência de Educação para o Desenvolvimento; Ed. de Cultura, 2003/2004. (Coleção para debater, 2).

ROBERTSON, Roland. Globalization: social theory and global culture. London: SAGE, 1992. (Collection Theory, Culture \& Society, 16).

Globalisation or glocalisation? Journal of International Communication, v. 1, n. 1, pp. 33-52, 1994.

. Glocalization: time-space and homogeneity-heterogeneity. In: FEATHERSTONE, Mike; LASH, Scott; ROBERTSON; Roland (Ed.). Global Modernities. London: Sage, 1995. pp. 25-44.

ROBERTSON, Roland; GUILANOTTI, Richard. Glocalization, transnational corporations and democratic governance: an analysis of the globalization of football. In: LOSCHE, Peter; RUGE, Undine; STOLZ, Klaus (Ed.). Year book of European and North American studies. Goettingen: University of Goettingen Press, 2001. v. 5. pp. 219-251.

ROBERTSON, Roland. Le dimensioni della cultura globale. In: BATINI, Elisabetta; RAGIONIERI, Rodolfo (Ed.). Culture e conflitti nella globalizzazione. Florence: Leo S. Olschki. 2002. pp. 17-30.

ROBERTSON, Roland; White, Kathleen E. Globalization: an overview. In: (Ed.). Globalization: critical concepts in sociology. London: Routledge, 2003. v. 1. pp. 1-44.

RUBIM, Antonio Albino C. O lugar da política na sociabilidade contemporânea. In: PRADO, José Luiz Aidar; SOVIK, Liv. (Org.). Lugar global e lugar nenhum: ensaios sobre democracia e globalização. São Paulo: Hacker, 2001. pp. 115-140.

SEDDA, Franciscu. (Org.). Glocal: sul presente a venire. Roma: Luca Sossella, 2004.

TRIVINHO, Eugênio. Cyberspace: crítica da nova comunicação. São Paulo: Biblioteca da ECA/USP, 1999. 466p. . A dromocracia cibercultural: lógica da vida humana na civilização mediática avançada. São Paulo: $\overline{\text { Paulus, }} 2007$.

VIRILIO, Paul. Vitesse et information: alerte dans le cyberespace! Le Monde Diplomatique, Août 1995. p. 28. [Versão em inglês: Speed and information: cyberspace alarm! In: CTheory.net. Disponível em: <http://www. ctheory.net/articles.aspx?id=72>. Acesso em: 24 out. 2012. . A bomba informática. São Paulo: Estação Liberdade, 1999.

\section{NOTAS}

1 Essa depreensão não se modifica em relação a casos mais recentes de política corporativa que prevê, sob a cobertura de uma megamarca com matriz global de gerenciamento em país diverso, a fabricação de produtos autorizados em países economicamente emergentes ou subdesenvolvidos, para satisfazer 
demandas mundiais e, em particular, os mercados desses países. Preservada a teia de relações transnacionais sob o eixo de uma imagem corporativa, a subordinação do local ao global jamais se dissolve; antes, situada em estrutura modificada, ganha (enquanto se reforçam) novas dimensões e matizes: ao se descolar de processos operacionais e de custeio estritamente atrelados à matriz, suspendem-se os laços de dependência econômica (mas não tanto os de obediência contratual delegada) em prol de sua decantação e instalação ao nível simbólico (da megamarca co-partilhada). O contexto local do país associado passa a cuidar, com autonomia, da cadeia produtiva inteira, até mesmo sem transferência de recursos econômicos à matriz, mas o capital de inovação, vinculado à megamarca, prevalece na patente de origem.

2 Uma rápida pesquisa pelo termo na Web, via qualquer browser, pode bem demonstrá-lo com sobejos resultados.

3 O assunto é retomado adiante.

4 Para uma reflexão desdobrada sobre este último tema, veja-se Trivinho (1999, Parte II, Capítulo 8). 